\title{
Erratum to: Cork and Sustainability: Discussing the Sustainable Use of the Material from a Design Perspective
}

\author{
PEREIRA Ana Carina ${ }^{1,2 *}, \quad$ BREZET Han ${ }^{1}$, PEREIRA Helena ${ }^{2}, \quad$ VOGTLÄNDER Joost ${ }^{1}$ \\ (1. Design for Sustainability, Faculty Industrial Design Engineering, Delft University of \\ Technology, 2628 CE Delft, TheNetherlands; 2. Forest Research Centre, School of \\ Agronomy, Technical University of Lisbon, Lisbon 1349-017, Portugal)
}

(C) Shanghai Jiaotong University and Springer-Verlag Berlin Heidelberg 2012

The original version of this article unfortunately contained several mistakes. The corrected items are given below.

(1) The authors' names should be: PEREIRA Ana Carina, BREZET Han, PEREIRA Helena, VOGTLÄNDER Joost.

(2) In the following locations, "is application" should be "are applications": the second sentence in the first paragraph in Section 0; the first sentence in the third paragraph in Section 1.

(3) In the last sentence of the third paragraph in Subsection 2.1, "after 9-year cycle" should be "after a 9-year cycle".

(4) In the end of Refs. [7, 10, 15, 20, 24], "(in Portuguese)" should be added.

The online version of the original article can be found at http://dx.doi.org/10.1007/s12204-012-1287-8.

*E-mail: a.c.dasilvapereira@tudelft.nl 